\title{
Origin of the Multinucleate Decidual Cell of the Mouse
}

\author{
E. B. Ilgren ${ }^{1}$, E. P. Evans', and M. D. Burtenshaw ${ }^{2}$
}

Received July 1, 1981

Polyploidy plays an important role in the evolution and differentiation of plant and animal tissues (Nagl 1978). Polyploid nuclei contain multiples of the haploid number (n) of chromosomes $(<2 \mathrm{n})$ and are, moreover, frequently 'giant' since they often times have more than four times the haploid (c) amount of nuclear DNA $(<4 \bar{c})$. In addition, "a cell containing two diploid nuclei must be regarded functionally and genetically as a tetraploid" (D'Amato 1977). Thus, multinucleate cells, or those containing more than two nuclei, are often 'functionally' polyploid. In mammals, multinucleates may be found in bone (Chamber 1978), skeletal muscle (Kaldaron 1980), bone marrow (Japa 1943), placenta (Billington 1971), liver (Wilson and Leduc 1948), decidua (Ansell et al. 1974), and nerve (Penfield 1932). Their occurrence elsewhere is usually pathological (Chambers 1978). On the basis of nuclear number and presumptive mode of origin, it is possible to distinguish roughly two types of multinucleates. The first are those with as many as fifty to one hundred nuclei and virtually no included mitotic figures. These are present within skeletal muscle, bone, and human trophoblast and presumably arise through the fusion of myoblastic (Kalderon 1980), osteoclastic (Chambers 1978) and cytotrophoblastic (Billington 1971) precursors. The second type of multinucleate, however, is generally smaller than the first and usually contains fewer than fifteen nuclei. It is found, moreover, within rodent liver (Wilson and Leduc 1948), nerve (Penfield 1932), bone marrow (Japa 1943), bovine trophoblast (Wimsatt 1951), and mouse decidua (Ansell et al. 1974). Although the manner in which this second type of multinucleate cell arises is not entirely clear, certain observations still offer a clue as to its origin. For example, multipolar mitotic figures have been found, on rare occasions, in aged rodent hepatocytes (Wilson et al. 1948); multiple metaphase nuclei noted within megakaryocytes (Japa 1943); polyploid metaphases and giant nuclei discovered in neural tissues (Willmer 1970, Brodskii et al. 1971) and decidua (Sachs and Shelesnyak 1955, Dupont et al. 1971, Zybina and Grischenko 1972); and mitotic nuclei found within the trinucleate cells of ruminant trophoblast (Wimsatt 1951). Such findings suggest that at least some of these multinucleates, in contrast to those of the first 'type', arise through multipolar polyploid mitoses that proceed in the absence of cytokinesis. However, according to Therman and Oksala (1974) "multipolar divisions are nearly absent from normal tissues" and occur far more often in malignant than in nonneoplastic conditions. Therefore, the present study was aimed at obtaining further proof that at least some multinucleates may arise via multipolar mitotic cycles since such findings could, in turn, provide additional insight into the origins of the poly-

1 Botany School, Sir William Dunn School of Pathology, University of Oxford, South Parks Road, Oxford.

2 MRC External Unit, Sir William Dunn School of Pathology, University of Oxford. 
ploid condition and possibly the tumourous state as well. For this purpose, the decidual tissues of the mouse were analysed cytologically and cytophotometrically. These were selected because their rate of cell division (Finn 1977) is generally much higher than that of mature liver (Carriere 1969), brain (Jacobson 1978), and giant trophoblast (Wimsatt 1951). Thus, it should be easier to find multipolar, mitotic figures in decidua than in hepatic, neural, or trophoblastic tissues. During the present investigation, multipolar mitoses were found in mouse decidua and these contained not only excessive amounts of nuclear DNA $(>4 \bar{c})$ but also numerous sets of chromosomes $(>2 n)$. Furthermore, these multipolar, mitotic figures were located almost exclusively within the antimesometrially-situated decidua, an area known to contain far more giant nuclei and multinucleate cells than any other decidual region (Ansell et al. 1974, Krehbiel 1937). Thus, during the growth of mouse decidua, multinucleation probably results from a multipolar nuclear division without concomitant cytokinesis; polyploidisation becomes, in turn, consequential upon multinucleation; and regionalisation can apparently influence the origin of the multinucleate, polyploid condition.

\section{Methods}

\section{Animals and the handling of tissues}

Random-bred CFLP albino mice (Anglia Laboratory) were used. Oestrous females were placed with males and mating ascertained the next morning by the presence of a copulation plug (Day 0 of pregnancy). Ovulation was assumed to occur at the midpoint of the dark period.

All animals were killed by cervical dislocation and tissues dissected in $\mathrm{PBI}$ medium (Whittingham and Wales 1969) plus $10 \%$ foetal calf serum (Flow). Decidual swellings were removed from uteri on the eithth day of pregnancy. Pseudopregnancy was induced by mating oestrous females with vasectomised males. On the third day of pseudopregnancy, animals were anaesthetised with $0.6 \mathrm{ml}$ avertin (Wintrobe; made up in PBS; $0.12 \mathrm{ml}$ avertin: $10 \mathrm{ml}$ PBS; intraperit.). Then, $0.5 \mathrm{ml}$ of Arachis oil was injected intraluminally through the oviductal end of the right uterine horn. Four days later, the pseudopregnant recipients were killed and the deciduomata removed.

\section{Microdensitometry}

Freshly dissected decidua were prepared in two ways. Some decidua were initially separated into 'antimesometrial' and 'mesometrial' fractions, the insertion of Reichert's membrane being taken as the dividing line between these two regions. Afterwards, each region was smeared individually onto an acidcleaned slide, fixed in 3 abs. alcohol: acetic acid ( $5 \mathrm{~min}$ ) and post-fixed in $85 \mathrm{abs}$. alcohol:10 formalin:5 acetic acid $(60 \mathrm{~min})$. Other decidua were not dissected but were fixed immediately in Bouin's solution, embedded in paraffin wax $\left(56^{\circ} \mathrm{C}\right)$ and then sectioned serially at $5 \mu$. Subsequently, all smears and tissue sections were Feulgen-stained using a standardised technique described elsewhere (Ilgren 1980a, b). Imprints of adult mouse liver, prepared in a manner similar to the smears of decidua, were also placed 
on to each slide to provide standards of known DNA content. Embryonic ectodermal metaphases found within Feulgen-stained, tissue sections also served as controls. Thus, 'ring-shaped' metaphases were selected for DNA measurement in order to avoid errors potentially attributable to variations in the distribution of chromatin (Goldstein and Bedi 1974). In addition, mitotic figures were scanned only if the preceding and following sections did not contain any portion of that nucleus. All nuclear DNA measurements were carried out with a Vickers microdensitometer $(\lambda=585 \mathrm{~nm})$. Finally, tissues used for cytophotometrical study were never treated with colcemid since this agent is known to induce spindle abnormalities and multipolarity (Sutou and Arai 1975).
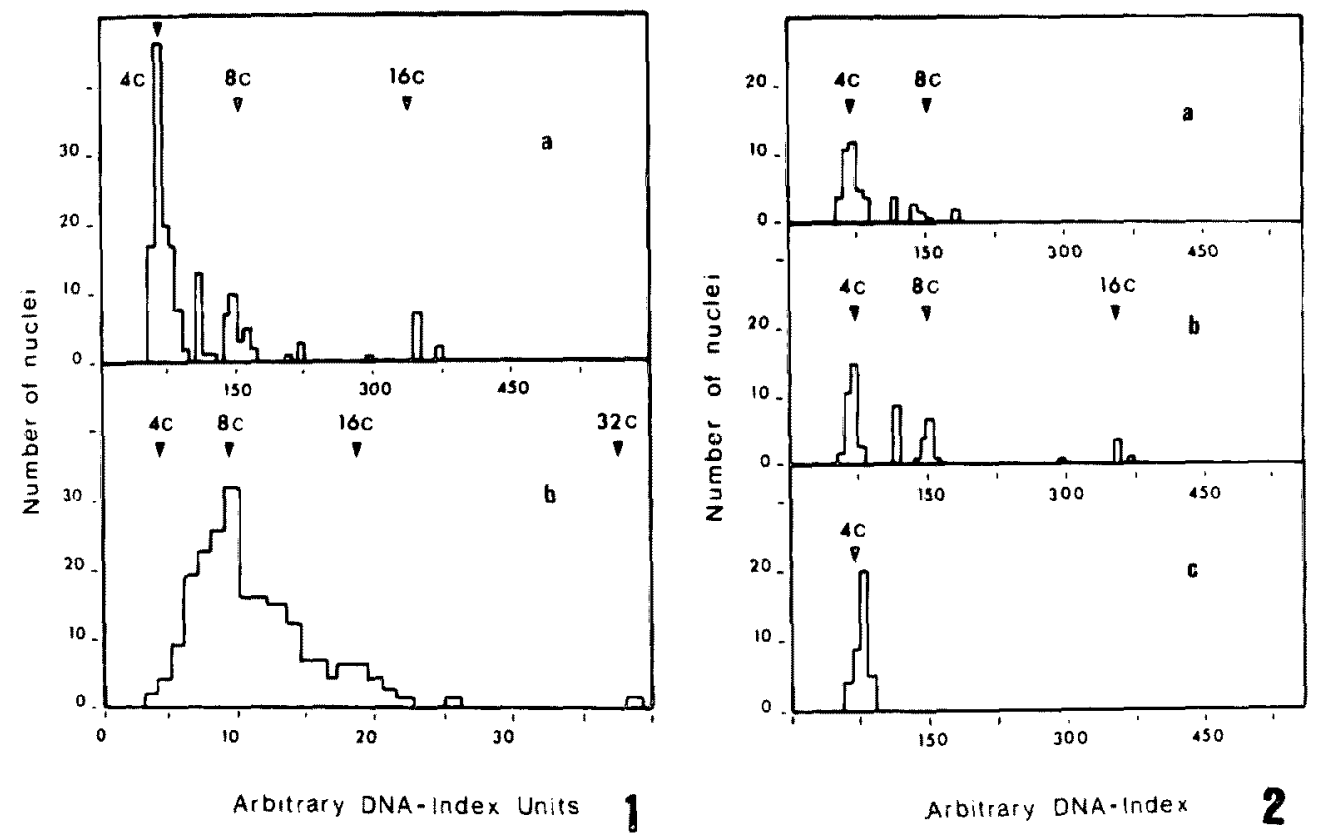

Figs. 1-2, 1, nuclear DNA contents of mitotic figures found in antimesometrially-situated decidual tissues. (a) Smears of oil-induced deciduomata $(n=167)$ and $(b)$ sections of embryo-derived $(n=$ 341). Note mitotic figures with intermediate DNA values in (a) and (b). Prophase nuclei not included. 2, nuclear DNA contents of (a) one-half telophase $(n=52),(b)$ metaphase $(n=73)$, and (c) one-half anaphase $(\mathrm{n}=43)$ nuclei found in sections of anti-mesometrially-situated, embryoderived, decidua. Scanned under oil.

\section{Chromosome analysis}

Decidual tissues were prepared using a modification of a method developed by Evans, Burtenshaw and Ford (1972) in order to obtain metaphases for chromosome analysis. Thus, 7.5 day pregnant and pseudopregnant mice were injected intraperitoneally with Colcemid $(0.1 \mathrm{ml} / \mathrm{gm}$ body wt.) (Grand Is Biol). After 75 minutes, each animal was killed and the decidual swellings removed. These were then transferred to hypotonic solution $\left(1 \% \mathrm{NA}^{+}\right.$Citrate; $\left.\mathrm{pH} 8.45 ; 26^{\circ} \mathrm{C} ; 20-22 \mathrm{~min}\right)$ and fixed ( 3 abs. methanol A. R.: acetic acid ( $1-2 \mathrm{hrs})$. Subsequently, decidual tissues were dissociated in $60 \%$ acetic acid $\left(26^{\circ} \mathrm{C}\right.$ ) on acid-cleaned slides (chromic acid followed by methanol: $\mathrm{HCl}$ ). Once dry, all preparations were stained with $0.66 \%$ 
aq. toluidine blue sol. Unstained slides prepared for chromosome analysis were also put through the Feulgen-staining procedure in an attempt to correlate ploidy evel (n) with nuclear DNA content $(\bar{c})$. Such preparations, however, usually failed
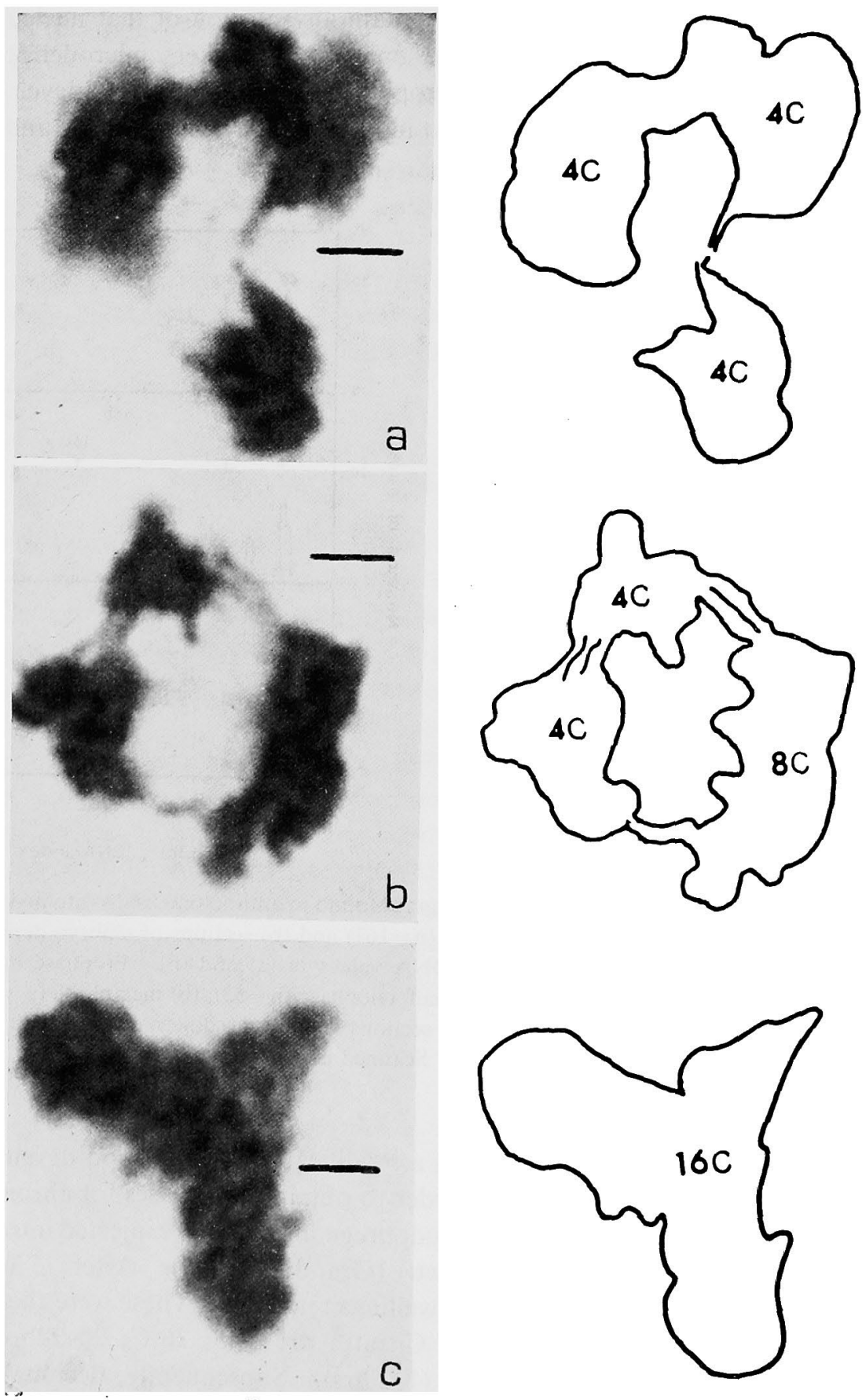

Fig. 3. Tripolar mitotic figures in (a) and (b) are in anaphse and (c) metaphase all from embryoderived, anti-mesometrially-situated, decidual tissues. Feulgen. Bar represents $0.1 \mu \mathrm{m}$. 
to stain with Feulgen due, in all likelihood, to an extensive loss of nucleic acid (Baker 1966).

\section{Results}

Eighty-six Feulgen-stained sections of decidua, taken from eight embryos and four litters of mice, were scanned cytophotometrically $(\times 1000$, oil). Fifteen oilinduced decidua taken from an additional twelve mice were used for nuclear DNA measurements and chromosome counts.

Microdensitometry: Giant mitotic figures were found in smears of oil-induced decidua (Fig. 1a) as well as sections of embryo-derived (Fig. 1b) decidual tissues and
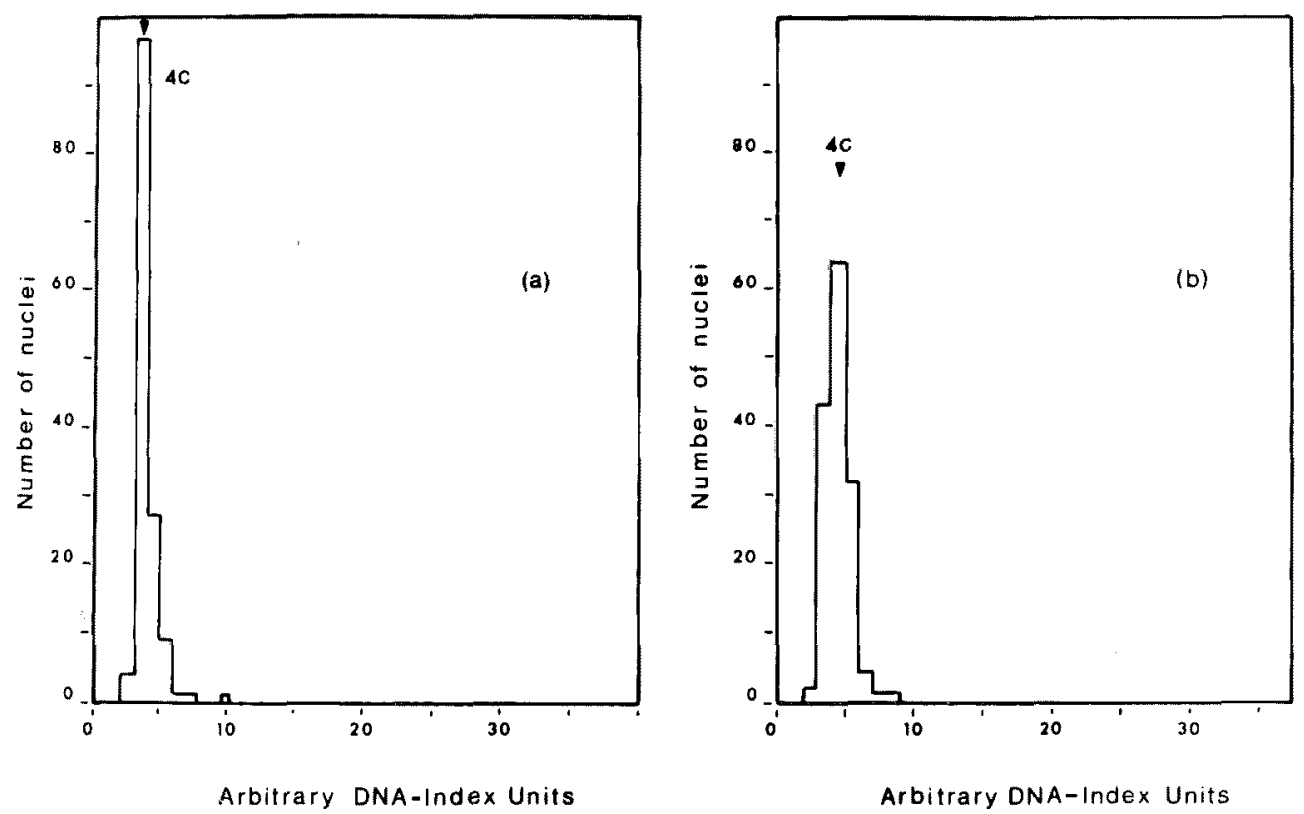

Fig. 4. Nuclear DNA contents of metaphases found in (a) smears of mesometrially-situated, oilinduced decidua $(n=294)$ and (b) section of embryonic ectoderm $(n=264)$. Note absence of giant mitotic figures.

were, moreover, confined largely to the antimesometrially-situated decidua. These were also noted to be in telophase (Fig. 2a), metaphse (Fig. 2b) and anaphase (Fig. 2c). The antimesometrially-situated decidua contained, most commonly, bipolar mitotic figures but occasionally tripolar forms (Fig. 3) and, in rare instances, mitotic figures with as many as six poles were also seen. Most of these giant mitotic figures had nuclear DNA contents which fell within descrete resting peaks ranging from $4 \bar{c}$ to $32 \bar{c}$ but a small number had intermediate DNA values of $6 \bar{c}$ and $12 \bar{c}$ (Fig. 1 and 2). Although the individual poles of these multipolar mitotic figures were not always identical in nuclear DNA content, they never possessed DNA values other than $2 \bar{c}, 4 \bar{c}, 8 \bar{c}$ or $16 \bar{c}$ (Fig. 3). By contrast, metaphases found within mesometriallysituated decidual tissues (Fig. 4a) and embryonic ectoderm (Fig. 4b) were exclusively

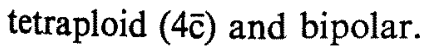


Chromosome analysis: Polyploid metaphases and anaphases were consistently recovered from the antimesometrial decidua (Fig. 5) but rarely, if ever, found within the mesometrially-situated decidual tissues or embyronic ectoderm. Such polyploid mitotic figures had up to 320 chromosomes ( $<1 \%$ of all metaphases),

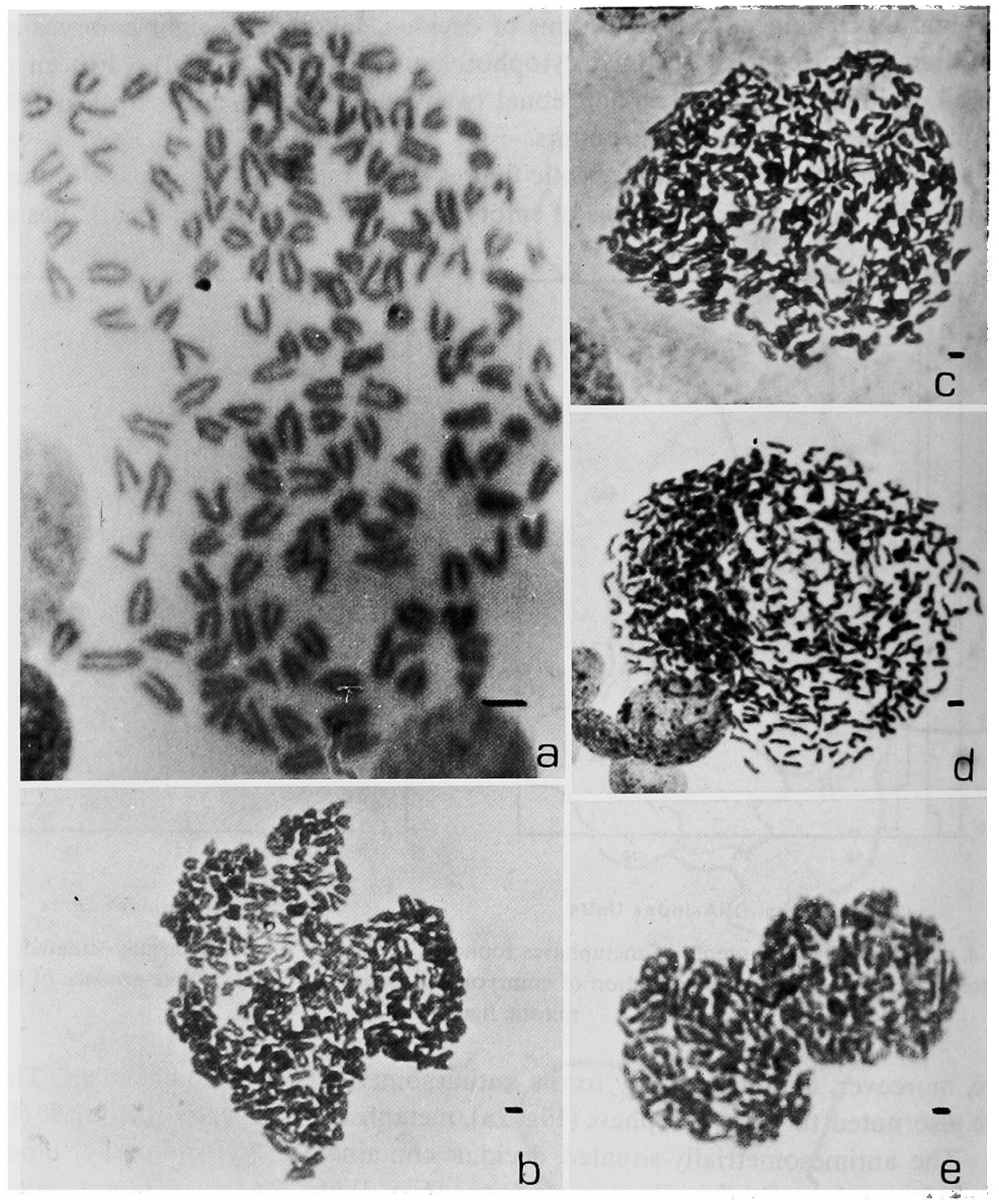

Fig. 5. Polyploid metaphases recovered from antimesometrially-situated oil-induced, deciduomata where (a) and (e) have approximately 160 chromosomes and (b). (c), and (d) over 300 chromosomes. Air-dried prep. s; Note (e) is probably from a binucleate cell and (b) a tripolar metaphase figure. Toluidine blue. Bar represents $0.1 \mu \mathrm{m}$.

counts presumably corresponding to those rare mitotic figures with $32 \overline{\mathbf{c}}$ nuclear DNA contents described in the preceding section. Large metaphases with more than 600 chromosomes were also found but extensive crowding and overlap made these impossible to count accurately. The latter, in contrast to the other polyploid 


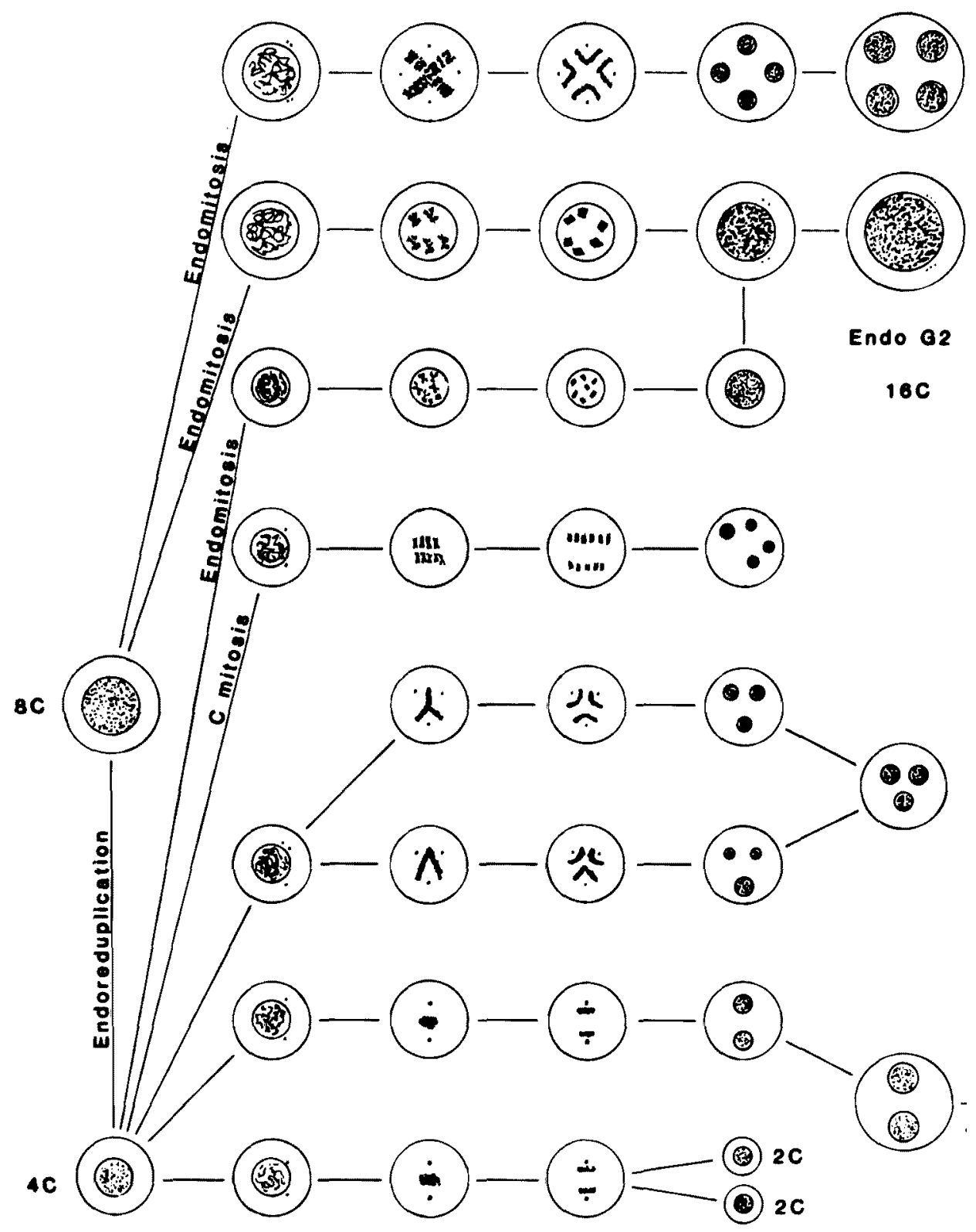

Interphase Prophase Metaphase Anaphase Interphase

$\mathbf{C 2}$

G 1

Fig. 6. Schematic diagram depicting the possible ways by which multipolar mitotic cycles and endocycles. During the present stı nucleates were never seen, e.g. trinucleates with two haploid (1C) absence of certain stages suggests that decidual multinucleates ma (e.g. see Teplitz et al. 1968 and tetrapolar mitosis). Alternative of multinucleates may be due to the fact that some stages are $\mathrm{m}$ leterious effects of various cytological reagents such as hypotor 
metaphases were still held within an intact nuclear membrane and thus appeared to be examples of endomitotic nuclei. Mitotic figures with diplochromosomes and polytenic structures were never seen and in only one instance was a tripolar metaphase with discernible chromosomes ever found (Fig. 5).

\section{Discussion}

\section{Multipolar mitoses and the formation of multinucleate cells}

Cells destined to become multinucleate may, upon entering late metaphase or telophase fail to undergo cytokinesis. Then, depending largely upon the organisation of the metaphase plate and the number of spindle poles and centrioles (Therman and Oksala 1974), the resultant multinucleate will usually contain between two and fourteen nuclei (Heneen et al. 1970). The decidual multinucleates found in this study generally had three or four nuclei. This observation is consistent with the fact that tri- and quadripolar metaphases were the most common type of multipolar mitotic figure found in mouse decidua (also see Pera and Schwarzacher 1968 for tripolars). However, in other tissues, the number of complex, multipolar mitoses $(<4$ poles) may actually outnumber both the tripolar and the quadripolar forms (e. g. Heneen et al. 1970, Levis and Maris 1963). Although metaphases with six poles were seen within the decidual cells, mitotic figures similar to those found in some virus-induced multinucleates with higher degrees of polarity (e. g. Heneen et al. 1970) were not observed in the decidua. Multipolarity is not strictly correlated with multinucleation. Hence, a multipolar metaphase that does not complete nuclear division may form a uninucleate cell rather than one with many nuclei (Nagl 1978, Levis 1962).

\section{Endocycles and the formation of multinucleate cells}

Endocycles refer to rounds of DNA replication that occur within an intact nuclear envelope without spindle formation (Nagl 1978). Moreover, endocycles take place either by endoreduplication or endomitosis ( $\mathrm{Nagl} \mathrm{1978).} \mathrm{In} \mathrm{an} \mathrm{endoreduplica-}$ tion cycle, there are only two phases namely, "Endo-G" and "Endo-S" and chromatin condensation does not occur (also see Fig. 6). Endomitotic cells not only have an 'Endo G and S' but also undergo chromatin condensation and chromosome formation during Endo-prophase and Endo-metaphase respectively (Fig. 6 and Nagl 1978). Multinucleation per se is not consequential upon endoreduplication and endomitosis. However, multinucleation, multipolarity, and the endocycle appear to be closely associated cellular processes. Thus, endomitotic and endoreduplicated nuclei are frequently found within multinucleate cells (Therman and Oksala 1974). Furthermore, endoreduplicated 'diplochromosomes' are often seen within multipolar, endometaphase plates (Heneen et al. 1970). This probably comes about when endomitosis follows an endoreduplication cycle during which chromosome replication and centriolar duplication takes place (e. g. Schmid 1966). Finally, complex, multipolar metaphases ( $<4$ poles) often undergo at least one endocycle prior to (endo) mitosis and thus have nuclear DNA contents that are almost always greater than $8 \overline{\mathbf{c}}$. 
The basis for the regionalization of the polyploid, multipolar mitotic figures within the anti-mesometrially-situated decidua is entirely unclear. It does not, however, seem to be an embryo-dependent phenomenon since the patterns of polyploidy found within oil-induced and embryo-derived decidual tissues appear to be similar (Krehbiel 1937, Zhinkin and Samoshkina 1967).

Contamination by other polyploid tissues (e. g. trophoblast (Barlow and Sherman 1972; amnion and yolk sac (Ilgren 1980a) cannot account for these results since comparable numbers of multinucleate giant cells and multipolar mitotic figures were found in deciduomata and decidua. Spurious nuclear DNA measurements due to sectioning artefact and nuclear fragmentation are unlikely since DNA values can be accurately determined on sectioned nuclei (e. g. Paulus 1968). The actual nuclear DNA contents of the giant mitotic figures may have been slightly underestimated since they were somewhat more contracted than embryonic ectodermal metaphases (Goldstein and Bedi 1974). Nevertheless, distortion was probably minimal since their chromatin was routinely distributed within the plane of histological section.

Although multinucleate decidual cells could also arise via cell fusion, certain observations make this unlikely. For example, the fact that GPI-IAB heteropolymer was never found in decidua chimaeric for the two electrophoretic variants of the enzyme glucose phosphate isomerase (GPI) (Ansell et al. 1974), strongly suggests that cell fusion had not occurred. Still, less than $5 \%$ of all mouse decidual cells are multinucleate, a figure approaching the maximum sensitivity of the GPI assay, i. e. 1-3\% (Chapman et al. 1972, Chapman et al. 1971). Thus, cell fusion might have occurred but was merely undetected. This is equally unlikely however if it is assumed that the bi, tri, and quadrinucleates are formed in a similar manner, since $30 \%$ of all rodent decidual cells are binucleate (Krehbiel 1937) and this figure greatly exceeds the sensitivity of the GPI assay. Thus, cell fusion if it occurs at all, is probably a rare event.

\section{Abstract}

Cytological and cytophotometrical analyses have shown that multipolar mitotic figures and multinucleate cells are present within mouse decidua. These are, moreover, found exclusively within the antimesometrially-situated decidua and contain not only excessive amounts of nuclear DNA $(>4 \bar{c})$ but also numerous sets of chromosomes $(>2 n)$. Thus, during the growth of mouse decidua, multinucleation probably results from a multipolar nuclear division without concomitant cytokinesis; polyploidisation becomes consequential upon multinucleation; and regionalisation can influence the origin of the multinucleate, polyploid condition.

\section{Acknowledgements}

We should like to thank Professor R. L. Gardner, Dr. C. G. Vosa, Dr. A. J. Copp, Dr. F. A. L. Clowes, Dr. P. W. Barlow, and our laboratory colleagues for valuable criticisms and Miss R. A. Woolston and Miss B. Brown for excellent techni- 
cal assistance. This work was initiated whilst EBI was a fellow of the International Agency for Research and Cancer (IACR/R. 882) and the American Cancer Society (SPF-14) and completed under a fellowship to EBI from the National Institutes of Health (IF32-HD-05592-01x1). This work was begun in the Department of Zoology, Oxford under Professor J. W. Pringle and finished in the Botany School, Oxford, under Professor R. Whatley and the Sir William Dunn Shool of Pathology, under Professor H. Harris. We are grateful to the Heads of each of these departments and their staff for their generous support. I should also like to thank Mrs. H. Holloway for excellent secretarial assistance.

\section{References}

Ansell, J. D., Barlow, P. W. and McLaren, A. 1974. Binucleate and polyploid cells in the decidua of the mouse. J. Emb. Exp. Morph. 31: 223-227.

Baker, J. 1966. Cytological Technique. The principles underlying routine methods. Chapman and Hall: London, $149 \mathrm{pp}$.

Barlow, P. W. and Sherman, M. I. 1972. The biochemistry of differentiation of mouse trophoblast: Studies on polyploidy. J. Emb. Exp. Morph. 27: 447-465.

Billington, W. D. 1971. The Biology of Trophoblast. Advances in Reproductive Physiology, 5 (ed. M.W.H. Bishop), Logos press: London, pgs. 27-66.

Brodskii, V. Ya., Sokolova, G. A. and Manakova, T. E. 1971. Multiple increases of DNA content in Purkinje cells in the ontogency of the rat. Ontogenez 2: 33-36.

Carriere, R. 1969. The growth of liver parenchymal nuclei and its endocrine regulation. Intl. Rev. Cytol. 25: 201-227.

Chambers, T. J. 1978. Multinucleate giant cells. J. Path. 126: 125-148.

Chapman, V. M., Whitten, W. K. and Ruddle, F. H. 1971. The expression of paternal glucose phosphate isomerase (GPI-1) in preimplantation stages of mouse embryos. Devl. Biol. 26: 153-158.

-, Ansell, J. D. and McLaren, A. 1972. Trophoblast differentiation in the mouse: expression of glucose phosphate isomerase (GPI-1) electrophoretic variants in transferred and chimaeric embryos. Devl. Biol. 29 : 48-54.

D'Amato, F. 1977. Nuclear Cytology in Relation to Development. Cambridge University Press: London, $283 \mathrm{pp}$.

Dupont, H., Duluc, J. A. and Mayer, G. 1971. Evolution cytologique et genese de la polyploidie dans le deciduome experimentale chez la Ratten en gestation unilaterale. C. R. Acad. (Paris) 272: 2360-2363.

Evans, E. P., Burtenshaw, M. D. and Ford, C. E. 1972. Chromosomes of mouse embryos and newborn young: preparations from membranes and tail tips. Stain Tech. 47: 229-234.

Finn, C. A. 1977. The implantation reaction In: The Biology of the Uterus (ed. R. M. Wynn), Plenum: N.Y., pgs. 246-308.

Goldstein, D. J. and Bedi, K. S. 1974. Cytophotometric factors causing apparent differences between Feulgen-DNA contents of different lymphocytes. Nature 241 : 439-440.

Heneen, W. K., Nichols, W. W., Levan, A. and Norby, E. 1970. Polykaryocytosis and mitosis in a human cell line after treatment with measles virus. Hereditas 64: 53-64 .

Ilgren, E. B. 1980a. Polyploidization of extraembryonic tissues during mouse embryogenesis. J. Emb. Exp. Morph. 59: 103-111.

- 1980b. On the control of trophoblastic growth in the guinea pig. J. Emb. Exp. Morph. 60: 405-418.

Jacobson, M. 1978. The germinal cell and the histogenesis of the nervous system, In: Developmental Neurobiology, Second edition, Plenum: N.Y., pgs. $27-57$.

Japa, J. 1943. A study of the morphology and development of the megakaryocyte. Brit. J. Exp. Path. 24: 83-80. 
Kalderon, W. 1980. Muscle cell fusion. In: Membrane-Membrane Interactions (ed. N. B. Gilula), Raven Press: New York, pgs. 99-118.

Krehbiel, R. 1937. Cytological study of the decidual reaction in the rat during early pregnancy and in the production of deciduomata. Physiol. Zool. 10: 212-233.

Levis, A. G. 1962. Effetti dei rozzi x sulla mitosi di cellule di mammiferi cultivate in vitro. Caryologia 15 : 59-87.

- and Maris, G. 1963. Induction of multipolar spindles by $\mathrm{x}$-irradiation in mammalian cells in vitro. Exp. Cell Res. 31: 448-451.

Nagl, W. 1978. Endopolyploidy and Polyteny in Differentiation and Evolution. N. Holland: Amsterdam, 283 pp.

Paulus, J. M. 1968. Etude ultrastructrate et microphotometrique de la maturation megacaryocytaire. Nouv. Rev. Hemat. 8: 394-397.

Penfield, W. 1932. Cytology and Cellular Pathology of the Nervous System (ed. W. Penfield), Hoeber: N.Y.

Pera, F. and Schwarzacher, H. 1968. Formation and division of binucleated cells in kidney cell cultures of microtus agrestis. Humangenetik 6: 158-162.

Sachs, L. and Shelesnyak, M. 1955 . The development and suppression of polyploidy in the developing and suppressed deciduomata in the rat. J. Endo. 12: 146-151.

Schmid, W. 1966. Multipolar spindles after endoreduplication. Exp. Cell Res. 42: 201-204.

Sutou, S. and Arai, Y. 1975. Possible mechanisms of endoreduplication induction. Exp. Cell Res. 92: 15-22.

Teplita, R. L., Gustafson, P. E. and Pellett, O. L. 1968. Chromosomal distribution in interspecific in vitro hybrid cells. Exp. Cell Res. $52: 379-391$.

Therman, E. and Oksala, T, 1974. Mitotic abnormalities and cancer. In: Chromosomes and Cancer (ed. T. German), Wiley and Sons: N.Y., pgs. 239-263.

Whittingham, D. E. and Wales, R. E. 1969. Storage of two-cell mouse embryos in vitro. Austral. J. Biol. Sci. 22: 1065-1068.

Willmer, E. N. 1970. Nerve cells, neuroglia, and schwann cells. In: Cytology and Evolution (Second edition), Acad. Press. N.Y. pgs. 106-120 (Figs. 5 and 6).

Wilson, J. W. and Leduc, E. G. 1948. The occurrence and formation of binucleate cells and polyploid nuclei in mouse liver. Amer. J. Anat. 82: 353;392.

Wimsatt, W. A. 1951. Observations on the morphogenesis, cytochemistry, and significance of the binculeate giant cells of the placenta of ruminants. Amer. J. Anat. 89: 233-282.

Zhinkin, L. N. and Samoshkina, N. A. 1967. DNA synthesis and cell proliferation during the formation of deciduomata in mice. J. Emb. Exp. Morph. 17: 593-506.

Zybina, E. and Grischenko, T. 1972. Spectrophotometrical estimation of ploidy level in decidual cells of the endometrium of the white rat. Tsitologiya 14: 284-290. 